\title{
NILAI-NILAI PENDIDIKAN \\ DALAM KELOMPOK SEBAYA
}

\author{
Gustina \\ Program Studi Pendidikan Agama Islam Jurusan Tarbiyah STAIN Batusangkar \\ Korespondensi: Perumahan Dobok Indah Blok A No.4 Batusangkar, Sumatera Barat \\ e-mail: gustinastain@yahoo.co.id
}

\begin{abstract}
A group of the same age was the second environment for specific individu in interacting with others in his/her environment. It became an intercation medium by this group to explore their knowledge. In real life, it usually took much influence on students' attitude rather than parents' influence. The group might play an important role on one's characteristic such as way of thinking, knowledge, understanding, attitude, interest, hobby, wish, performance, and behaviour in daily activities. Therefore, educational value had to be kept and developed in this group was as follows: the value of honest, initiative, responsibility, groupwork, wanting to share, respectfulness, discipline, and so on.
\end{abstract}

Kata kunci: nilai pendidikan, kelompok sebaya

\section{PENDAHULUAN}

$\mathrm{M}$ anusia adalah makhluk terbaik ciptaan Allah Swt yang dijadikan sebagai khalifah di muka bumi. Dalam mewujudkan kekhalifahannya, manusia tidak dapat hidup sendirian sehingga membutuhkan orang lain. Dengan demikian manusia juga disebut sebagai makhluk individual dan makhluk sosial. Sebagai makhluk sosial, manusia berinteraksi dan bersosialisasi dengan orang lain dalam menjalankan kehidupannya. Sarana dan wahana tempat bersosialisasi dan berinteraksi yang pertama adalah dalam lingkungan keluarga.

Kelompok sebaya adalah lingkungan kedua setelah keluarga. Kelompok sebaya merupakan salah satu wahana interaksi sosial individu yang sangat berpengaruh penting sepanjang hidup seseorang, bahkan sangat berpengaruh penting pada tahap perkembangan anak dan remaja.Pernyataan ini diperkuat oleh Havighurst, (1984: 32) yang menegaskan bahwa pengalaman anak-anak dalam peer-group sangat penting dalam tugas-tugas pokok perkembangan anak-anak sekolah. Anakanak didorong oleh desakan batin ke dalam group activity, atau disebut orang juga periode ini sebagai "social hunger".

Dalam banyak pengalaman kehidupan, pengaruh kelompok sebaya seringkali mengalahkan pengaruh orangtua, terutama pada masa remaja. Kelompok sebaya menyediakan suatu lingkungan, yaitu tempat teman sebayanya dapat melakukan sosialisasi dengan nilai yang berlaku, bukan lagi nilai yang ditetapkan oleh orang dewasa, melainkan oleh teman seusianya, dan tempat dalam rangka menentukan jatidirinya, namun apabila nilai yang dikembangkan dalam kelompok sebaya adalah nilai negatif, maka akan menimbulkan bahaya bagi perkembangan jiwa individu. 
Kuatnya pengaruh kelompok sebaya juga mengakibatkan melemahnya ikatan individu dengan orang tua, sekolah, norma-norma yang berlaku. Selain itu, banyak waktu yang diluangkan individu di luar rumah bersama teman-teman sebayanya dari pada dengan orangtuanya adalah salah satu alasan mendasar dan krusial bahwa peran teman sebaya bagi individu sangatlah penting. Peranan penting kelompok sebaya terhadap individu berkaitan dengan cara berpikir, pengetahuan, pemahaman, sikap, minat, hobi, cita-cita, penampilan, dan perilakunya dalam kehidupan seharihari. Anggota kelompok sebaya seringkali meniru temannya baik dalam berpakaian maupun dalam berperilaku. Misalnya anggota kelompok sebaya yang laki-laki memakai anting atau kalung di kaki merupakan kebanggaan dan dipandang ngetren dan mengikuti zaman.

Berpijak pada kajian konseptual dan kecenderungan persoalan yang dikemukakan di atas, maka sangat urgen dieksplorasi nilai-nilai pendidikan yang didapatkan dalam kelompok sebaya. Sehingga yang berkembang itu adalah nilai-nilai yang positif dalam kehidupan masyarakat.

\section{PENGERTIAN PENDIDIKAN}

Pengertian pendidikan yang paling mutakhir sampai saat ini adalah pengertian pendidikan yang dimuat dalam Undang-Undang Nomor 20 Tahun 2003 pasal 1 ayat 1 tentang Sistem Pendidikan Nasional yaitu:Pendidikan adalah usaha sadar dan terencana untuk mewujudkan suasana belajar dan proses pembelajaran agar peserta didik secara aktif mengembangkan potensi dirinya untuk memiliki kekuatan spiritual keagamaan, pengendalian diri, kepribadian, kecerdasan, akhlak mulia, serta keterampilan yang diperlukan dirinya, masyarakat, bangsa dan negara.
Prayitno (2009: 37) menjelaskan bahwa inti dari pendidikan adalah belajar. Oleh karena itu, tanpa adanya suasana belajar dan proses pembelajaran maka tidak ada pendidikan. Ada lima dimensi belajar yaitu: (1) dimensi Tahu: dari tidak tahu menjadi tahu; (2) dimensi bisa: dari tidak bisa menjadi bisa; (3) dimensi mau: dari tidak mau menjadi mau; (4) dimensi biasa: dari tidak biasa menjadi biasa; dan (5) dimensi ikhlas: dari tidak ikhlas menjadi ikhlas.

Prayitno (2009: 59) menjelaskan ada dua pilar pembelajaran yaitu kewibawaan dan kewiyataan. Kewibawaan mencakup pengakuan dan penerimaan, kasih sayang dan kelembutan, penguatan, tindakan tegas yang mendidik, serta pengarahan dan keteladanan. Sedangkan kewiyataan mencakup materi pembelajaran, metode pembelajaran, alat bantu pembelajaran, lingkungan pembelajaran, dan penilaian hasil pembelajaran.

Proses pendidikan sangat erat kaitannya dengan situasi sosial dan budaya. Pendidikan itu sendiri merupa-kan hasil dari kebudayaan manusia, dan melalui pendidikan itu juga terjadinya proses transmisi budaya. Oleh karena pendidikan merupakan proses transmisi budaya, maka aktor dari proses interaksi sosial akan sangat berperan dalam pembelajaran, aktor tersebut adalah guru atau pendidik.

Pendidikan dan kebudayaan adalah sesuatu yang tidak dapat dipisahkan, oleh karena itu metode pendidikan dan pembelajaran mesti memperhatikan tipe dan tradisi masyarakat yang menerima pendidikan. Ada dua tipe masyarakat yaitu masyarakat yang membentuk hubungan primer dan masyarakat yang membentuk hubungan sekunder (Abdullah Idi, 2011: 61-62). Masyarakat dengan hubungan primer biasanya memiliki hubungan yang sangat dekat antar sesama anggotanya, akrab, murni, penuh rasa cinta, sama rasa, alamiah dan biasanya kekal. Hubungan yang semacam ini 
biasanya ditemukan di masyarakat pedesaan. Sedangkan masyarakat dengan hubungan sekunder membentuk hubungan dengan pamrih, kesepakatan, perjanjian, dan biasanya relatif singkat. Hubungan seperti ini biasanya ditemukan di wilayah perkotaan dan kawasan industri.

S. Nasution dalam Abdullah Idi (2011: 61) menjelaskan bahwa pada dasarnya pendidikan berfungsi untuk menyiapkan individu menjadi anggota masyarakat yang berguna. Oleh karena itu, isi pendidikan itu sebenarnya adalah kebudayaan, dengan menguasai kebudayaan maka individu mampu hidup beradaptasi di lingkungan masyarakat.

Pendidikan dapat berlangsung kapan saja dan di mana saja dengan syarat adanya pendidik, ada peserta didik, dan materi pembelajaran. Peserta didik dan atau pendidik dapat siapa saja, baik yang usianya lebih tua, lebih muda, ataupun teman sebaya. Apabila terjadi penguasaan tentang sesuatu yang baru, maka proses belajar telah terjadi.

\section{PENGERTIAN KELOMPOK SE- BAYA}

Untuk mendapatkan pemahaman yang memadai dan kompleks tentang makna kelompok sebaya terlebih dahulu penulis jelaskan pengertian kelompok dan kelompok sosial. Beberapa definisi kelompok, di antaranya adalah diungkapkan oleh Joseph S. Roucek bahwa suatu kelompok meliputi dua atau lebih manusia yang di antara mereka terdapat beberapa pola interaksi yang dapat dipahami para anggotanya atau orang lain secara keseluruhan. Menurut Mayor Polak kelompok sosial adalah suatu group, yaitu sejumlah orang yang ada hubungan antara satu dengan yang lain dan hubungan itu bersifat sebagai sebuah struktur. Jadi, dapat diungkapkan bahwa kelompok dalam perspektif sosiologi adalah sekumpulan dua orang atau lebih yang saling berinteraksi dan terjadi hubungan timbal balik di mana mereka merasa menjadi bagian dari kelompok tersebut. (Abdullah Idi, 2011: 117-118)

Siti Norma (2007: 23) menjelaskan bahwa kelompok-kelompok sosial merupakan kesatuan sosial yang terdiri dari kumpulan individu-individu yang hidup bersama dengan mengadakan hubungan timbal balik yang cukup intensif dan teratur, sehingga dari padanya diharapkan adanya pembagian tugas, struktur, serta norma-norma tertentu yang berlaku bagi mereka.

Kelompok sosial dibedakan menurut beberapa kategori yaitu dari segi besaran anggota kelompok terbagi dalam kelompok primer dan kelompok sekunder. Kelompok primer anggotanya kecil sehingga hubungan intensif dan saling mengenal secara lebih dalam serta sifatnya permanen, contohnya keluarga. Sedangkan kelompok sekunder, jumlah anggotanya cukup banyak, mereka tidak perlu saling mengenal secara pribadi, dan tidak bersifat permanen. Selain itu, ada juga kelompok formal dan informal. Kelompok formal diikat oleh peraturan yang formal seperti PGRI, KORPRI, dan lain sebagainya. Sedangkan kelompok informal tidak diikat oleh peraturan resmi, misalnya remaja mesjid, kelompok pengajian dan arisan.

Menurut S. Nasution (2009: 46), kelompok-kelompok sosial tidak saja berdampak positif, namun juga sering menjadi tempat bagi individu untuk belajar berprasangka terhadap kelompok lain yang dianggap mengancam atau yang sering disebut etnosentris.

J. Dwi Narwoko dan Bagong Suyanto (2007: 94) kelompok bermainbaik yang berasal dari kerabat, tetangga maupun teman sekolah-merupakan agen sosialisasi yang pengaruhnya besar dalam membentuk pola-pola perilaku seseorang. Melalui kelompok bermain, anak mempelajari berbagai kemampuan baru yang seringkali berbeda dari apa yang mereka pelajari dari keluarga. Di 
dalam kelompok bermain individu mempelajari norma nilai, kultural, peran, dan semua persyaratan lainnya yang dibutuhkan individu untuk memungkinkan partisipasinya yang efektif dalam kelompok permainannya. Singkatnya, kelompok bermain ikut menentukan dalam pembentukan sikap untuk berperilaku yang sesuai dengan perilaku kelompoknya.

Berdasarkan pemahaman dan pengertian dari kelompok dan kelompok sosial yang telah didiskusikan di atas, maka dapat diartikan bahwa kelompok sebaya adalah suatu tatanan interaksi antara anak-anak atau remaja yang memiliki usia atau tingkat kematangan yang relatif sama dengan kawankawannya sebaya yang memiliki peran yang unik dalam kehidupannya seharihari.

\section{LATAR BELAKANG TIMBULNYA KELOMPOK SEBAYA}

Beberapa hal yang melatarbelakangi timbulnya kelompok sebaya adalah: Pertama, adanya perkembangan proses sosialisasi. Pada usia remaja (usia anak SMP dan SMA), individu mengalami proses sosialisasi, di mana mereka itu sedang belajar memperoleh kemantapan sosial dalam mempersiapkan diri untuk menjadi orang dewasa yang baru. Sehingga individu mencari kelompok yang sesuai dengan keinginannya, di mana individu bisa saling berinteraksi satu sama lain dan merasa diterima dalam kelompok.

Kedua, kebutuhan untuk menerima penghargaan. Secara psikologis, individu butuh penghargaan dari orang lain, agar mendapat kepuasan dari apa yang telah dicapainya. Oleh karena itu individu bergabung dengan teman sebayanya yang mempunyai kebutuhan psikologis yang sama yaitu ingin dihargai. Sehingga individu merasakan kebersama- an/kekompakan dalam kelompok teman sebayanya.

Ketiga, perlu perhatian dari orang lain. Individu perlu perhatian dari orang lain terutama yang merasa senasib dengan dirinya. Hal ini dapat ditemukan dalam kelompok sebayanya, di mana individu merasa sama satu dengan yang lainnya, mereka tidak merasakan adanya perbedaan status, seperti jika mereka bergabung dengan dunia orang dewasa.

Keempat, ingin menemukan dunianya. Di dalam peer group individu dapat menemukan dunianya, di mana berbeda dengan dunia orang dewasa. Mereka mempunyai persamaan pembicaraan di segala bidang. Misalnya: pembicaraan tentang hobi dan hal-hal yang menarik lainnya.

\section{FUNGSI KELOMPOK SEBAYA}

Kelompok sebaya sebagai salah satu jenis kelompok sosial mempunyai fungsi strategis mencapai tujuan pendidikan. Di antara fungsi kelompok sebaya adalah sebagai berikut: Pertama, mengajarkan kebudayaan. Dalam kelompok sebaya ini berkembang kebiasaan dan budaya yang berada di lingkungan tersebut. Misalnya: orang Minangkabau pergi ke Malaysia, maka afiliasi kelompok sebaya di Malaysia belajar tentang budaya Minang. Dalam kehidupannya sehari-hari, terjadi interaksi dan sosialisasi yang mengakibatkan terjadi transaksi budaya antara budaya Minang dengan budaya Melayu Malaysia. Mereka sama-sama belajar tentang budaya, belajar bahasa Minang, kebiasaan orang Minang, belajar masakan Minang yang terkenal dengan Randang Padang.

Kedua, mengajarkan mobilitas sosial. Mobillitas sosial adalah perubahan status yang lain. Misalnya ada kelas menengah dan kelas rendah (tingkat sosial). Dengan adanya kelas rendah pindah ke kelas menengah dinamakan mobilitas sosial. Dalam hal ini 
Neugarten mengadakan penyelidikan pada kelas V dan VI, mendapatkan data bahwa apabila mereka ditanya siapa teman mereka yang paling baik, kebanyakan mereka menunjuk anak yang berasal di atas sosial mereka, baru kemudian anak dari kelas mereka sendiri.

Ketiga, membantu peranan sosial yang baru. Kelompok sebaya memberi kesempatan bagi anggotanya untuk mengisi peranan sosial yang baru. Misalnya: anak yang belajar bagaimana menjadi pemimpin yang baik, dan sebagainya.Keempat, kelompok sosial sebagai sumber informasi bagi orang tua dan guru bahkan untuk masyarakat. Kelompok sebaya di sekolah bisa sebagai sumber informasi bagi guru dan orang tua tentang hubungan sosial individu dan seorang yang berprestasi baik dapat dibandingkan dalam kelompoknya. Kelompok sebaya di masyarakat sebagai sumber informasi, kalau salah satu anggotanya berhasil, maka di mata masyarakat kelompok sebaya itu berhasil. Atau sebaliknya, bila suatu kelompok sebaya itu sukses maka anggotaanggotanya juga baik.

Kelima, dalam kelompok sebaya, individu memiliki ketergantungan satu sama lain. Karena dalam kelompok sebaya ini mereka dapat merasakan kebersamaan dalam kelompok, mereka saling tergantung satu sama lainnya. Keenam, kelompok sebaya mengajar moral orang dewasa. Anggota kelompok sebaya bersikap dan bertingkah laku seperti orang dewasa, untuk mempersiapkan diri menjadi orang dewasa mereka memperoleh kemantapan sosial. Tingkah laku mereka seperti orang dewasa, tapi mereka tidak mau disebut dewasa. Mereka ingin melakukan segala sesuatu sendiri tanpa bantuan orang dewasa, mereka ingin menunjukkan bahwa mereka juga bisa berbuat seperti orang dewasa.

Ketujuh, di dalam kelompok sebaya, individu dapat mencapai kebebasan sendiri. Kebebasan di sini diartikan sebagai kebebasan untuk berpendapat, bertindak atau untuk menemukan identitas diri. Karena dalam kelompok itu, anggota-anggota yang lain juga mempunyai tujuan dan keinginan yang sama. Berbeda dengan kalau anak bergabung dengan orang dewasa, maka anak akan sulit untuk mengutarakan pendapat atau untuk bertindak, karena status orang dewasa selalu berada di atas dunia anak sebaya.

Kedelapan, di dalam kelompok sebaya, anak-anak mempunyai organisasi sosial yang baru. Anak belajar tentang tingkah laku yang baru, yang tidak terdapat dalam keluarga. Dalam keluarga yang strukturnya lebih sempit, anak belajar bagaimana menjadi anak dan saudara. Sekarang dalam kelompok sebaya mereka belajar tentang bagaimana menjadi teman, bagaimana mereka berorganisasi, bagaimana berhubungan dengan anggota kelompok yang lain, dan bagaimana menjadi seorang pemimpin dan pengikut. Kelompok sebaya menyediakan peranan yang cocok bagi anggotanya untuk mengisi peranan sosial yang baru.

Menurut S. Nasution (2009: 50) kelompok-kelompok sosial sangat mempengaruhi nilai-nilai yang dianut oleh anggota kelompoknya, seperti toleransi atau sebaliknya prasangka. Individu yang hidup dalam kelompok yang kurang berpendidikan cenderung bersikap prasangka terhadap kelompok lain, sebaliknya individu yang hidup dalam kelompok terdidik memiliki toleransi yang lebih tinggi.

Pembentukan kepribadian berawal sejak individu dilahirkan, dalam pembentukan kepribadian ini maka kelompoklah yang melakukannya, dan seseorang tidak akan bisa mengelak dari pengaruh kelompoknya (J. Dwi Narwoko dan Bagong Suyanto (2007: 85). 


\section{SOSIALISASI DALAM KELOM- POK SEBAYA}

J. Dwi Narwoko dan Bagong Suyanto (2007: 94) menjelaskan pola sosialisasi dalam kelompok sebaya berbeda dengan pola sosialisasi dalam keluarga. Pola sosialisasi dalam keluarga cenderung otoriter karena perbedaan usia dan derajat serta fungsi dalam keluarga, sedangkan pola sosialisasi dalam kelompok sebaya bersifat ekualitas karena kedudukan para anggotanya relatif sama.

Menurut Kimball Young dalam Ary H. Gunawan (2000: 33) sosialisasi adalah hubungan interaktif yang dengannya seseorang mempelajari keperluankeperluan sosial dan kultural, yang menjadikan seseorang sebagai anggota masyarakat.

Abdullah Idi (2011: 208) menjelaskan bahwa perubahan sosial merupakan perubahan dari segi struktural masyarakat seperti pola-pola perilaku dan pola interaksi anggota masyarakat; perubahan dari segi kultural masyarakat seperti nilai-nilai, sikap-sikap, serta normanorma sosial masyarakat.

\section{TUJUAN SOSIALISASI DALAM KELOMPOK SEBAYA}

J. Dwi Narwoko dan Bagong Suyanto (2007: 94) menjelaskan di dalam kelompok bermain individu mempelajari norma nilai, kultural, peran, dan semua persyaratan lainnya yang dibutuhkan individu untuk memungkinkan partisipasinya yang efektif dalam kelompok permainannya. Singkatnya, kelompok bermain ikut menentukan dalam pembentukan sikap untuk berperilaku yang sesuai dengan perilaku kelompoknya.

Efek dari interaksi sosial dalam kelompok tidaklah sama pada setiap orang. Sosialisasi dalam kelompok yang anggotanya masih anak-anak mempunyai pengaruh yang sangat besar dalam pembentukan pribadinya, namun semakin dewasa usia seseorang maka pengaruh kelompok semakin berkurang karena kepribadiannya semakin terbentuk (J. Dwi Narwoko dan Bagong Suyanto (2007: 87).

\section{PENUTUP}

Kelompok sebaya adalah lingkungan kedua bagi individu dalam berinteraksi dengan lingkungannya. Kelompok sebaya merupakan salah satu wahana interaksi sosial individu yang sangat berpengaruh penting sepanjang hidup seseorang, bahkan sangat berpengaruh penting pada tahap perkembangan anak dan remaja. Dalam banyak pengalaman kehidupan, pengaruh kelompok sebaya seringkali mengalahkan pengaruh orangtua, terutama pada masa remaja.

Kuatnya pengaruh kelompok sebaya juga mengakibatkan melemahnya ikatan individu dengan orang tua, sekolah, norma-norma yang berlaku. Selain itu, banyak waktu yang diluangkan individu di luar rumah bersama teman-teman sebayanya dari pada dengan orangtuanya adalah salah satu alasan mendasar dan krusial bahwa peran teman sebaya bagi individu sangatlah penting. Peranan penting kelompok sebaya terhadap individu berkaitan dengan cara berpikir, pengetahuan, pemahaman, sikap, minat, hobi, cita-cita, penampilan, dan perilakunya dalam kehidupan sehari-hari. Oleh sebab itu, nilai-nilai pendidikan yang penting dipertahankan dan dikembangkan dalam kelompok sebaya adalah: nilai-nilai kejujuran, inisiatif, tanggungjawab, kerjasama, kemauan berbagi, tenggang rasa, kesabaran, disiplin, semangat juang, kerja keras, dan lainnya. 


\section{DAFTAR RUJUKAN}

Batubara, M. 2004. Sosiologi Pendidikan. Jakarta: Ciputat Press.

Goode, W. 2007. Sosiologi Keluarga. Jakarta: Bumi Aksara.

Gunawan, A.H. 2010. Sosiologi Pendidikan: Suatu Analisis Sosiologi tentang Pelbagai Problem Pendidikan. Jakarta: Rineka Cipta.

Havighurst, R.J., 1984. Perkembangan Manusia dan Pendidikan. Bandung: Jemmars.

Idi, A. 2011. Sosiologi Pendidikan: Individu, Masyarakat, dan Pen- didikan. Jakarta: Rajagrafindo Persada.

Karsidi, R. 2007. Sosiologi Pendidikan. Surakarta: LPP UNS.

Prayitno, 2009. DasarTeori dan Praksis Pendidikan. Jakarta: Grasindo

Rifa"i, M. 2011. Sosiologi Pendidikan. Jogjakarta: Ar Ruzz Media.

S. Nasution. 2009. Sosiologi Pendidikan. Jakarta: Bumi Aksara.

Yusuf, C.F. 2008. Budaya Sekolah \& Mutu Pendidikan. Jakarta: Pena Citasatria, cet.1. 